\title{
Late Manifestation of Massive Jejunal and Cecal Varices Post Liver and Small Bowel Transplantation in a Patient With Microvillus Inclusion Disease
}

\author{
Shiva F. Naidoo ${ }^{1}$, Joshua C. Obuch ${ }^{2}$ \\ 1. Internal Medicine, Geisinger Health System, Wilkes-Barre, USA 2. Gastroenterology, Geisinger Health System, \\ Wilkes-Barre, USA
}

Corresponding author: Shiva F. Naidoo, shivanaidoo26@gmail.com

\begin{abstract}
We report the case of an 18-year-old male with a medical history of microvillous inclusion disease (MID) and notable surgical history of small bowel, liver, and pancreas transplant who presented with massive jejunal and cecal varices. Endoscopy findings demonstrated a large grape-like cluster, with subsequent CT angiography (CTA) showing other variceal lesions in the cecum. The patient was transferred to the original transplant center for recommended open surgical evaluation and combined interventional radiology (IR) embolization of varices. MID is a rare genetic disorder caused by mutations in the Myosin VB (MYO5B) gene leading to a lack of myosin $\mathrm{Vb}$. Patients subsequently develop liver damage at birth, which necessitates a small bowel/liver transplant in childhood.
\end{abstract}

Review began 05/22/2021 Review ended 06/15/2021 Published 06/24/2021

๑) Copyright 2021 Naidoo et al. This is an open access article distributed under the terms of the Creative Commons Attribution License CC-BY 4.0., which permits unrestricted use, distribution, and reproduction in any medium, provided the original author and source are credited.
Categories: Internal Medicine, Radiology, Gastroenterology

Keywords: gastric varices, upper gastro-intestinal bleed, acute gastrointestinal bleed, microvillus inclusion disease, jejunal varices, small bowel transplant, liver transplant

\section{Introduction}

Microvillus inclusion disease (MID) is a rare genetic disorder due to mutations in the Myosin VB (MYO5B) gene resulting in a lack of myosin $\mathrm{Vb}$. Patients who suffer from this condition cannot form microvilli and are total parenteral nutrition (TPN)-dependent from birth, which can lead to sequelae of liver damage. Treatment for patients affected by MID includes small bowel transplant and possible liver transplant in the setting of associated liver damage [1]. Jejunal varices are a rare cause of gastrointestinal (GI) bleeding with associated high mortality [2] and most often occur in the setting of portal hypertension. In this report, we discuss the case of an 18-year-old male with MID post small bowel and liver transplant in infancy who presented with recurrent GI bleeding as a consequence of jejunal varices.

\section{Case Presentation}

An 18-year-old male with a past medical history of MID and a notable surgical history of small bowel, liver, and pancreas transplant, who was maintained on tacrolimus $2 \mathrm{mg}$ and prophylactic trimethoprimsulfamethoxazole 400-80 mg, presented to the emergency room (ER) with four days of hematochezia and lightheadedness. He had experienced recurrent GI bleeding, most recently a year ago, and had undergone multiple endoscopies by pediatric gastroenterology in the past, which had been negative for active bleeding or any possible source. The patient denied nausea, vomiting, abdominal pain, fevers, shortness of breath, cough, or chest pain. His vitals on presentation were as follows: BP of 136/67 mmHg, heart rate (HR) of 114 beats per minute, respiratory rate (RR) of 22 breaths per minute, $\mathrm{O}_{2}$ saturation of $96 \%$ on room air, and temperature of $36.9^{\circ} \mathrm{C}$.

The serologic evaluation was pertinent for hemoglobin of $9.6 \mathrm{~g} / \mathrm{dL}$, white blood cell count of $4.66 \mathrm{~K} / \mathrm{uL}$, platelets of $130 \mathrm{~K} / \mathrm{uL}$, and prothrombin time (PT)-international normalized ratio (INR) of 1.152. Liver function tests including aspartate aminotransferase (AST), alanine aminotransferase (ALT), alkaline phosphatase (ALP), and bilirubin were all within normal limits. The patient was admitted and scheduled to undergo evaluation with esophagogastroduodenoscopy (EGD). The following day, he continued to deteriorate with ongoing bleeding resulting in a hemoglobin drop to $6.7 \mathrm{~g} / \mathrm{dL}$, requiring transfusion of one unit of packed red blood cells. EGD with push enteroscopy showed an enteroenterostomy with a hemorrhagic appearance in the jejunum. The area adjacent to the anastomosis was biopsied to rule out rejection. The region near the anastomosis had grape-like clustering raising concern for varices, and noted hemorrhage post-biopsy (Figure 1). Hemostasis was achieved with argon plasma coagulation and epinephrine (Figure 2). A metallic clip was placed for radiographic identification for the purpose of an interventional radiology (IR) procedure (Figure 3). Subsequently, the patient remained intubated and was transferred to ICU on an octreotide drip. 


\section{Cureus}

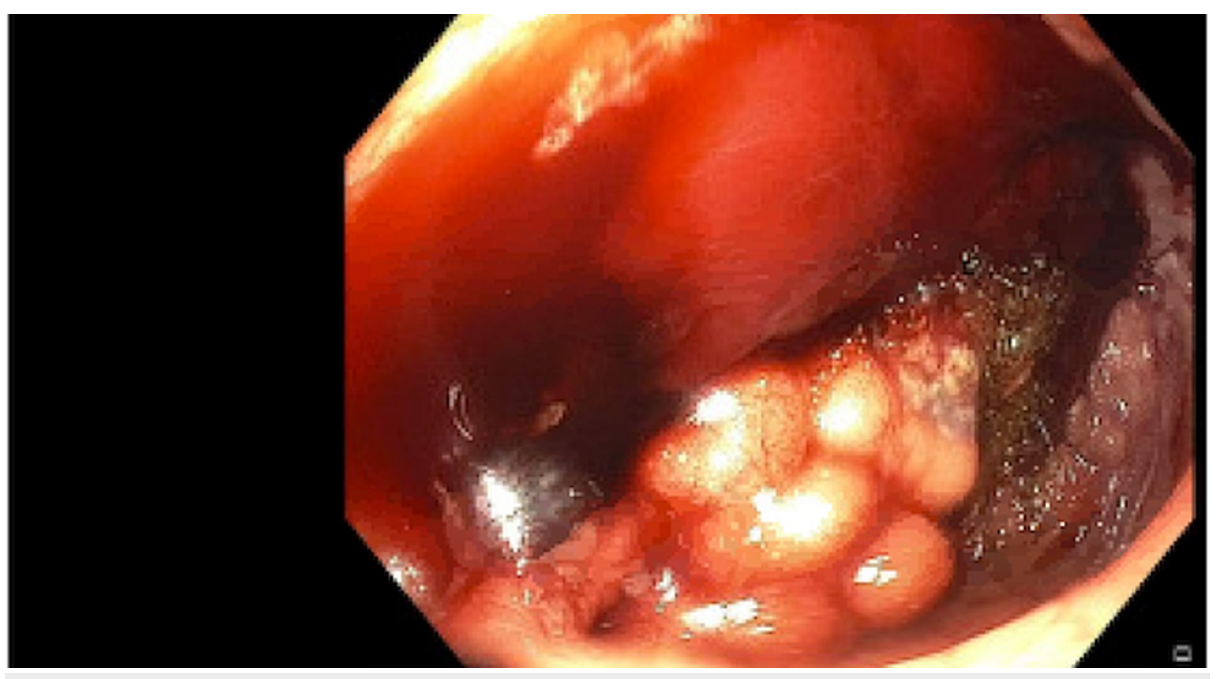

FIGURE 1: Hemorrhagic mucosa in proximal jejunum with varices

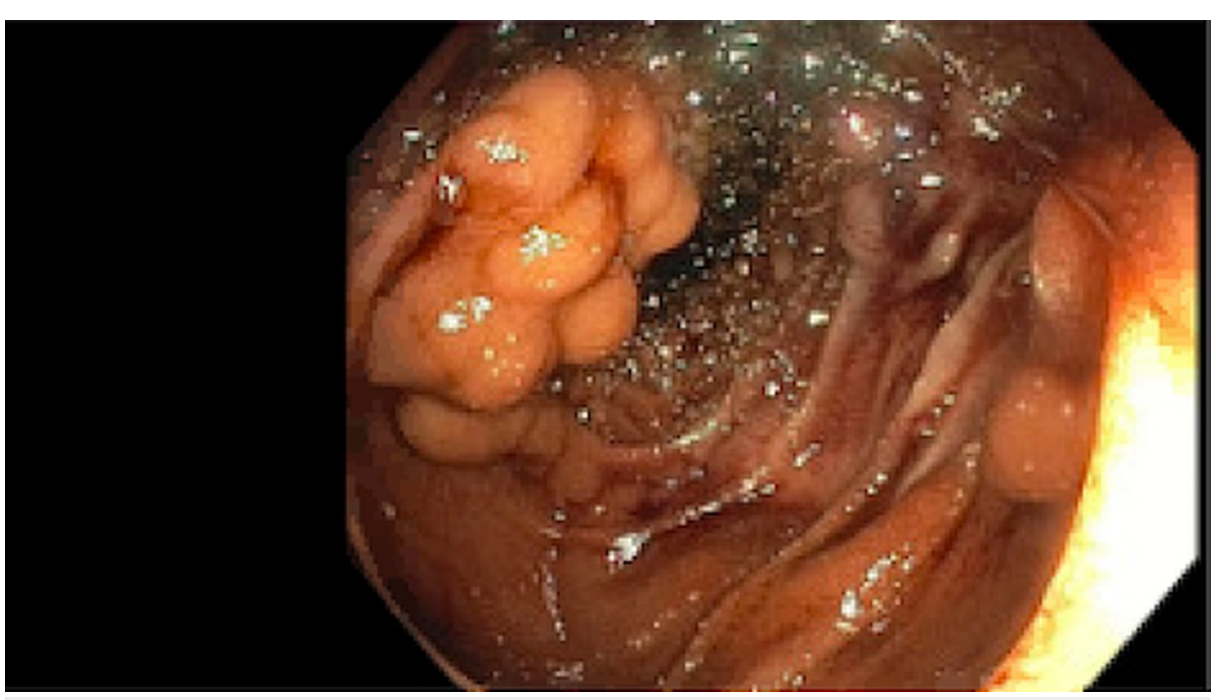

FIGURE 2: Post-bleeding biopsy with hemostasis achieved

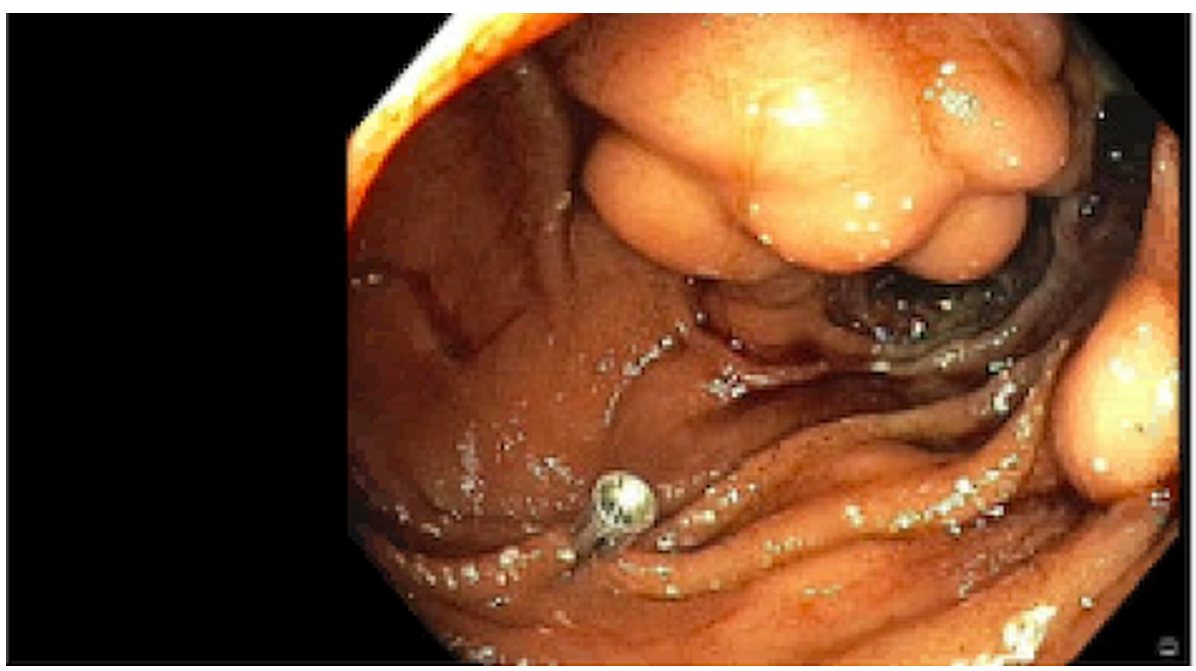

FIGURE 3: Metallic clip placed with hemostasis maintained 


\section{Cureus}

The case was discussed with IR and Transplant Hepatology, as endoscopic management with sclerosing agents or glue was not available. The complex nature of the post-surgical vascular anatomy and concern for an interrupted inferior vena cava prompted IR to perform a CT angiography (CTA) of the abdomen, with the possibility of embolization. The results of the CTA demonstrated a massive tangle of jejunal submucosal varices, as well as reported cecal submucosal varices and massive splenomegaly (Figures 4, 5). Furthermore, due to atrophic hepatic vein and systemic collaterals to the azygos vein, transjugular intrahepatic portosystemic shunting (TIPS) was deemed not feasible at the time. Subsequent discussion involving Transplant Surgery at the hospital where the patient had received his small bowel and liver transplant prompted a decision to transfer the patient for open surgical evaluation and combined IR embolization of varices. The patient was then stabilized and transferred.

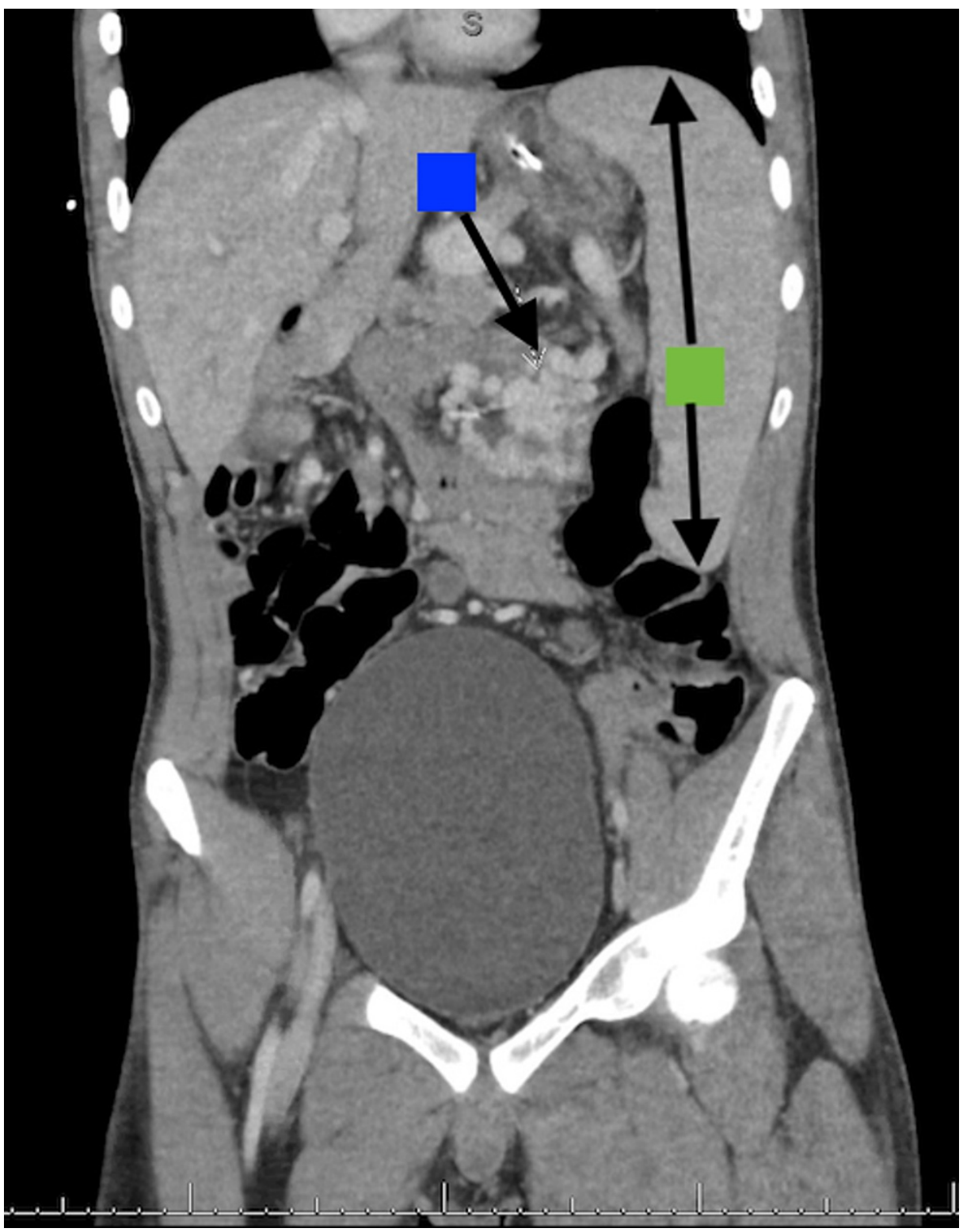

FIGURE 4: CT angiogram of the abdomen showing massive jejunal varices (blue arrow), and massive splenomegaly (green bidirectional arrow) of a craniocaudal length of $20 \mathrm{~cm}$

CT: computed tomography 


\section{Cureus}

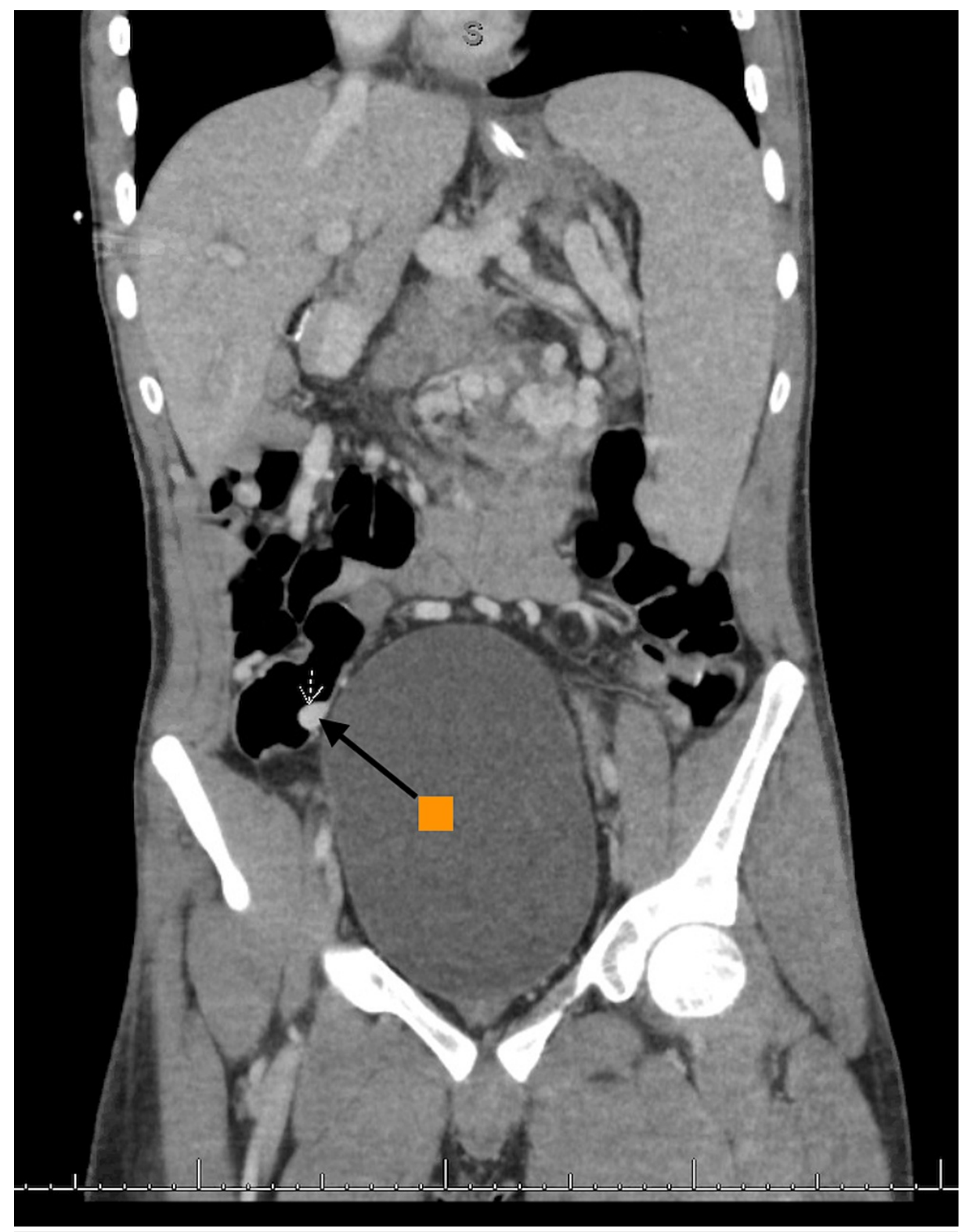

FIGURE 5: CT angiogram of the abdomen showing small second cluster of cecal varices (orange arrow)

CT: computed tomography

\section{Discussion}

Ectopic varices contribute to $2-5 \%$ of all GI bleeding [2]. Concurrently, there is also a four-fold higher risk of bleeding when compared to esophageal varices, with a mortality rate as high as $40 \%$ [3]. The causes of ectopic varices are varied, and patients with portal hypertension are at increased risk for developing them. In a systematic review of 169 patients with bleeding from ectopic varices, only $18 \%$ of intraabdominal bleeds were found to have originated at the jejunum and $7-12 \%$ demonstrated jejunal stomal or parastomal bleeds [4]. Also, prior abdominal surgery is a predisposing factor that can lead to jejunal varices [5]. Small-bowel varices can result from mesenteric hypertension, mediated by portal hypertension or mesenteric vein stenosis [6]. At the anastomotic site of the enteroenterostomy, small-bowel varices can occur, as demonstrated in this case. A complication of portal hypertension can present as jejunal varices and, in rare cases, cecal varices. A similar case report by Ayash et al. [7] has documented portal venous thrombosis from a Factor V Leiden deficiency manifesting as another cause of jejunal varices.

Unlike most cases, our patient had a unique and rare anatomic predisposition. The hepatic vein was atrophic, along with azygos collaterals to the superior vena cava that greatly contributed to the presence of portal hypertension. Generally, portal hypertension would affect the esophageal or gastric vessels [8]. However, the patient developed jejunal and cecal varies, despite undergoing multiple endoscopies in the 
The management of jejunal or ectopic varices can be challenging because of their varying locations and clinical presentations. Specialized techniques generally include surgical, endoscopic, or endovascular approaches. Surgical management may involve laparotomy with ligation of the vessel at the affected site [9]. Further intervention may extend as far as the resection of the location of the small bowel affected as well [10]. Endoscopic management may include obliteration of jejunal varices with the use of cyanoacrylate glue through a double-balloon enteroscopy [11]. Endovascular approaches include balloon-occluded retrograde transvenous obliteration, which is a technique that uses a specialized balloon catheter with a sclerosing agent to stop bleeding [12]. Another common modality employed is percutaneous embolization [13,14]. TIPS is a common treatment modality for ectopic variceal bleeding with portal hypertension, particularly in those associated with a recurrent risk of rebleeding [15]. Portal venous stent placement is a unique approach, in which portal hypertension itself is reduced and subsequent complications including ectopic varices are addressed [16].

\section{Conclusions}

MID is a rare condition, and its treatment includes a small bowel and/or liver transplant. Patients with a history of MID may present with massive jejunal and cecal varices manifesting as GI bleeding, and clinicians should be aware of this phenomenon.

\section{Additional Information \\ Disclosures}

Human subjects: Consent was obtained or waived by all participants in this study. Conflicts of interest: In compliance with the ICMJE uniform disclosure form, all authors declare the following: Payment/services info: All authors have declared that no financial support was received from any organization for the submitted work. Financial relationships: All authors have declared that they have no financial relationships at present or within the previous three years with any organizations that might have an interest in the submitted work. Other relationships: All authors have declared that there are no other relationships or activities that could appear to have influenced the submitted work.

\section{References}

1. Jayawardena D, Alrefai WA, Dudeja PK, Gill RK: Recent advances in understanding and managing malabsorption: focus on microvillus inclusion disease. F1000Res. 2019, 8:F1000. 10.12688/f1000research.20762.1

2. Saad WE, Lippert A, Saad NE, Caldwell S: Ectopic varices: anatomical classification, hemodynamic classification, and hemodynamic-based management. Tech Vasc Interv Radiol. 2013, 16:158-75. 10.1053/j.tvir.2013.02.004

3. Kochar N, Tripathi D, McAvoy NC, Ireland H, Redhead DN, Hayes PC: Bleeding ectopic varices in cirrhosis: the role of transjugular intrahepatic portosystemic stent shunts. Aliment Pharmacol Ther. 2008, 28:294303. 10.1111/j.1365-2036.2008.03719.x

4. Norton ID, Andrews JC, Kamath PS: Management of ectopic varices. Hepatology. 1998, 28:1154-8. 10.1002/hep.510280434

5. Yuki N, Kubo M, Noro Y, et al.: Jejunal varices as a cause of massive gastrointestinal bleeding . Am J Gastroenterol. 1992, 87:514-7.

6. Hiraoka K, Kondo S, Ambo Y, Hirano S, Omi M, Okushiba S, Katoh H: Portal venous dilatation and stenting for bleeding jejunal varices: report of two cases. Surg Today. 2001, 31:1008-11. 10.1007/s005950170013

7. Ayash A, Mushtaq K, Abdul Qader ME, Al-Ejji KM, Al Kaabi SR, Khelfa SJS: Jejunal varices bleeding in a patient with extensive portomesenteric thrombosis secondary to factor v Leiden mutation: a management dilemma. Case Rep Gastrointest Med. 2019, 2019:4526472. 10.1155/2019/4526472

8. Mumtaz K, Majid S, Shah H, Hameed K, Ahmed A, Hamid S, Jafri W: Prevalence of gastric varices and results of sclerotherapy with N-butyl 2 cyanoacrylate for controlling acute gastric variceal bleeding. World J Gastroenterol. 2007, 13:1247-51. 10.3748/wjg.v13.i8.1247

9. Kobayashi K, Yamaguchi J, Mizoe A, Isomoto I, Koshiishi T, Izawa K, Kanematsu T: Successful treatment of bleeding due to ileal varices in a patient with hepatocellular carcinoma. Eur J Gastroenterol Hepatol. 2001, 13:63-6. 10.1097/00042737-200101000-00012

10. Mashimo M, Hara J, Nitta A, et al.: A case of ruptured ileal varices associated with alcoholic liver cirrhosis (Article in Japanese). Nihon Shokakibyo Gakkai Zasshi. 2007, 104:561-7.

11. Hashimoto R, Sofue K, Takeuchi Y, Shibamoto K, Arai Y: Successful balloon-occluded retrograde transvenous obliteration for bleeding duodenal varices using cyanoacrylate. World J Gastroenterol. 2013, 19:951-4. 10.3748/wjg.v19.i6.951

12. Haruta I, Isobe Y, Ueno E, et al.: Balloon-occluded retrograde transvenous obliteration (BRTO), a promising nonsurgical therapy for ectopic varices: a case report of successful treatment of duodenal varices by BRTO. Am J Gastroenterol. 1996, 91:2594-7.

13. Saeki Y, Ide K, Kakizawa H, Ishikawa M, Tashiro H, Ohdan H: Controlling the bleeding of jejunal varices formed at the site of choledochojejunostomy: report of 2 cases and a review of the literature. Surg Today. 2013, 43:550-5. 10.1007/s00595-012-0243-4

14. Lim LG, Lee YM, Tan L, Chang S, Lim SG: Percutaneous paraumbilical embolization as an unconventional and successful treatment for bleeding jejunal varices. World J Gastroenterol. 2009, 15:3823-6. 


\section{Cureus}

10.3748/wig. 15.3823

15. Vangeli M, Patch D, Terreni N, Tibballs J, Watkinson A, Davies N, Burroughs AK: Bleeding ectopic varices-treatment with transjugular intrahepatic porto-systemic shunt (TIPS) and embolisation. J Hepatol. 2004, 41:560-6. 10.1016/j.jhep.2004.06.024

16. Yamakado K, Nakatsuka A, Tanaka N, Fujii A, Isaji S, Kawarada Y, Takeda K: Portal venous stent placement in patients with pancreatic and biliary neoplasms invading portal veins and causing portal hypertension: initial experience. Radiology. 2001, 220:150-6. 10.1148/radiology.220.1.r01j103150 